\title{
RECONDITIONING THE SEWERAGE AND DRINKING WATER SYSTEM WITHIN THE FACULTY OF MATHEMATICS, UNIVERSITY OF GUAYAQUIL, ECUADOR
}

\author{
ARMANDO SALTOS, PATRICIA VILLA, JACINTO ROJAS \& MANUEL GOMEZ DE LA TORRE \\ Faculty of Math and Physical Sciences, University of Guayaquil, Ecuador
}

\begin{abstract}
An evaluation of the sewer and rainwater systems, the same ones that currently discharge from the University of Guayaquil's main network, was carried out. These networks have previously exceeded their operational capacity, causing flooding in the rainy season. In addition, the drinking water supply system was evaluated. The evaluation identified interconnection problems between the rainwater and sewage networks. This research proposes improvements to the sewage systems with the design of new networks: to identify the flow of rainwater and sewers, avoid contamination of wastewater and minimize the impact of rainy season flooding. Installed capacity is currently insufficient, because the university population grew exponentially. The existing drinking water reservoirs made of asbestos cement are in bad condition; the pipes and accessories of the supply networks are corroded, as galvanized iron was used for their construction (materials widely used at that time). We established new potable water conduction networks, new sanitary units for the university's Faculty of Math and Physical Sciences building, and made the reconditioned sewage and rainwater networks work separately.

Keywords: drinking water, sewer systems, drainage, plumbing remodelling, rainwater, storage tank, building information modelling, Revit modelling, University of Guayaquil.
\end{abstract}

\section{INTRODUCTION}

The information used as a starting point for the development of this research included topographic surveys; records of sanitary units or public toilets; records of the storage system, such as tanks and cisterns and their pumping units; and the functionality of the plumbing systems, drinking water supply and sewers. The student population during 20182019 was also taken into account [1].

Before being evacuated, wastewater must meet certain quality parameters that meet the requirements for drinking water proposed by the World Health Organization (WHO) [2]. WHO and United Nations (UNICEF) have suggested action plans to ensure the continuous supply of safe water, sanitation and hygiene. In education centres, handwashing units with water and soap dispensers should be installed [3]. As technology advances, the efficiency of systems is improved. Based on this, many authors propose the installation of intelligent systems for water dispensers, to minimize the consumption of resources [4].

When designing the sanitary infrastructure, the elements must have dimensions according to the number of users [5]. The Norma Ecuatoriana de la Construcción (Ecuadorian Construction Standard) (NEC), establishes the minimum parameters to be met in all designs, before construction of hydro-sanitary installations. This, under normal conditions, ensures good functioning under quantity and quality expectations, in space and time inside the property, house, or building.

According to studies carried out in Japan, the toilet ventilation is recommended to be installed at the bottom of the walls, or at the sink level, to increase elimination of bad 
odours [6]. This approach was considered for this project's proposed ventilation system design.

Ottawa University has several publications where the sizing of the distribution network and the drinking water supply system are analysed. This methodology was applied to evaluate the actual conditions of the drinking water and sewer networks in the University of Guayaquil, Ecuador [7].

When designing sanitary infrastructure, the necessary equipment must be provided according to the number of users and their type, whether the population is steady or fluctuates [5].

There is simulation software that helps to determine the degree of uncertainty for rainwater collection. The uncertainty can be estimated considering different demand scenarios for drinking water, with hourly and daily variations in a normal distribution [8]. It is not common to store rainwater in Ecuador.

The most severe problems found in buildings are usually generated by the sanitary infrastructure, especially caused by pipe failures, due to corrosion, ruptures, deflections, etc.: These cause transport deficiencies in the drinking water system, as well as in wastewater discharge [9].

The functionality of sanitary installations should be evaluated before any redesign is performed. Surveys are a useful tool and should be conducted to evaluate user's perceptions of the operation of the sewer system, bad odours, and the ease of discharge of the effluent. The functionality of sanitary installations should be valued before any redesign is performed: This result should be contrasted with subsequent inspections.

The construction industry has taken a technological leap in project design with the implementation of computer tools such as Building Information Modelling (BIM), which facilitates the design, planning and reduction of project times and costs: This tool was used in our research.

For water pipeline installation modelling with BIM, it is necessary to acquire the operating parameters in advance, so the software can automatically generate the pipe diameters to be used and the pipeline routing without considering the sizing of the pipes. The software has some parameters that are required for the network layout, so it is necessary to identify these values [10].

BIM software has three different modelling suites, the Construction Model (CM), which works user's data; the BIM Design Model, used for evaluation; Evaluation Model, which uses data details [11]. This research project is based on determining solutions from the analysis of results obtained in Phase 1 of this research, where problems were found in the sanitary and drinking water networks in the Faculty of Mathematical and Physical Sciences (FMPS) building facilities in the University of Guayaquil.

In the proposal to be presented for the reconditioning of the drinking water and sewage systems, we considered: storage tanks, adaptations in the ventilation systems in sanitary pipelines, increases in the number of toilets, making the rainwater and sewage systems independent, a proposal for the construction of a cistern, and implementation of ditches for rainwater evacuation.

\section{METHODOLOGY AND MATERIALS}

Fig. 1 illustrates the methodology to be developed in the implementation of the proposed solution for the sewage, rainwater and drinking water networks of the FMPS building, based on the results obtained in the evaluation of the first phase of the project, where we determined there was a lack of toilets, deterioration of the drinking water tanks with their connections, and bad interconnections between the sanitary and storm sewer network. 
Information Gathering [1]

Statistical results of the student population, the degree of user satisfaction

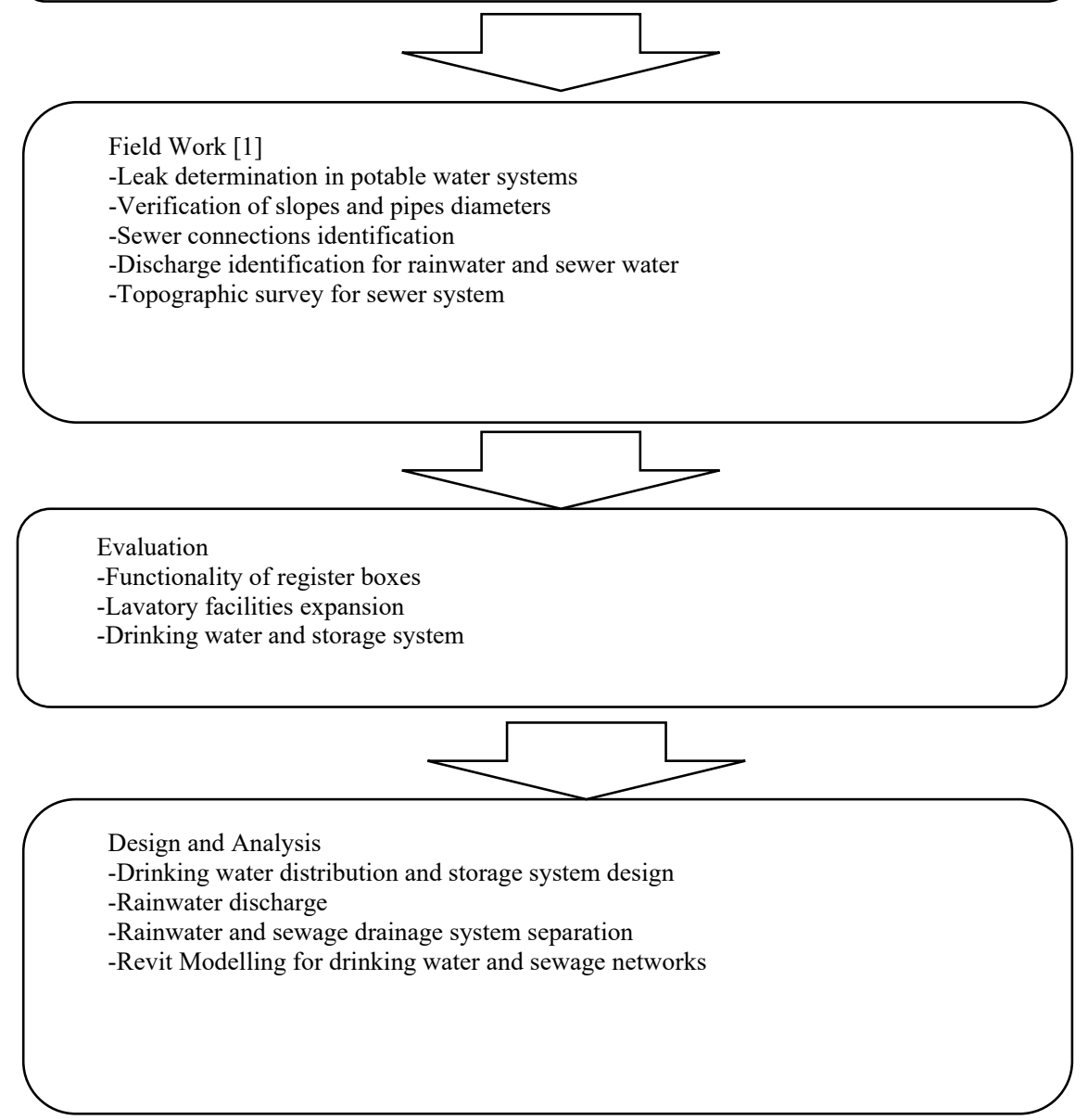

Figure 1: Applied methodology for the sewage and drinking water systems for the Faculty of Mathematical and Physical Sciences building in the University of Guayaquil.

In the evaluation carried out in the first phase of the project, surveys and the evaluation of the sewage and drinking water systems were included, they considered the existing student population during the period 2018-2019 and historical data from the last 20 years, the flows of two lines flowing in the FMPS building and its records.

After tabulating the surveys, generating the statistics for modelling, estimating the demand for water supply in the FMPS building, and the level of user satisfaction, our research continues with the final phase of the project, where solutions are proposed for the three different areas concerning sanitation. 
This methodology generates the proposed solution for the reconditioning of healthy drinking water systems of the FMPS building, once Phase 1 of the research project [1] has been completed, where information was collected through fieldwork to determine leaks, the definition of slopes in the network, state of the toilets, diameters of the collectors, topography and general evaluation of the functionality of the sanitary devices. The design and modelling was implemented using the diagrams generated in BIM.

\section{SANITARY SEWER SYSTEM}

According to the information collected from the sanitary sewer network located in the library and the physics laboratory area, the number of existing record boxes needed to be evaluated [1].

In the library area, there are seven wastewater registration boxes: Their discharges are concentrated in (under) the women's restrooms and the dining room on the ground floor. The men's restrooms on the first floor are interconnected with the main system in the postgraduate offices and computer lab area. The student's wellness bathroom and the dining room drainage are also connected into this system [1].

The rainwater discharge runs towards box \#4, as can be seen in Fig. 2. This box will be released and later connected directly to an evacuation channel, as shown in the proposed sewer solutions plan. The sewage water system located under the Physics laboratory is comprised of 11 interconnected boxes coming from eight restrooms and three from rainwater drainage.

The discharge system coming from the restrooms has very poor ventilation, as do the laboratory and library areas. Only the men's restrooms on the ground floor have good ventilation.

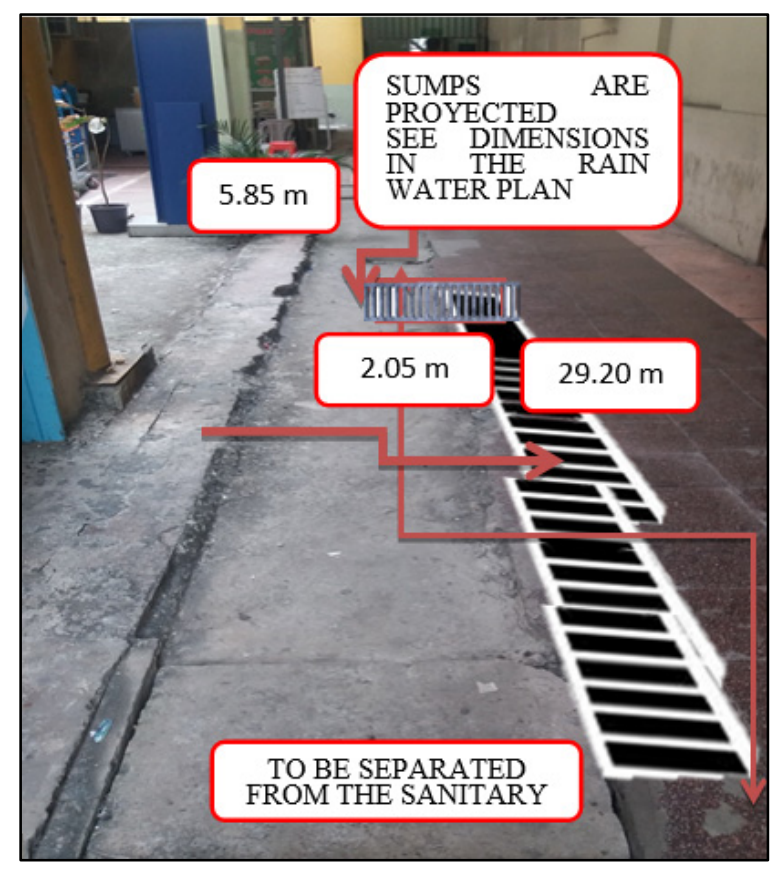

Figure 2: Rainwater evacuation channels and interconnections of the shelter with the Physics laboratory evacuation channels. 


\section{DRINKING WATER SYSTEM}

The flow rate must be measured to estimate the deliverability of the system under actual demand conditions. In one of the registration boxes, it was not possible to measure the flow rate, because it entered directly into a storage vessel. To measure the flow rate, the water feeding line had to be disconnected to document the flow rate.

Flow measurements were made in May, June, and July of the year 2019; registering an average flow value of $1.7 \mathrm{~m}^{3} / \mathrm{h}$, considering the two pipelines that supply each water storage vessel present [1].

The working hours of the FMPS building are considered in regular business days, starting at 7:00 and ending at 22:00, so to calculate water demand a time-lapse of $14 \mathrm{~h}$ was considered. As there are two supply lines of $1.7 \mathrm{~m}^{3} / \mathrm{h}$ each, simple math gives a total of about $82 \mathrm{~m}^{3}$ of water demand, throughout the day. Therefore, a security factor of about $20 \%$ over the calculated demand was considered, which gives a total estimate for need of $100 \mathrm{~m}^{3}[1]$.

According to the survey applied, as proposed in the methodology, a population of 2,500 permanent users was estimated for the FMPS building's facilities, this includes: teachers, students, administrative staff and maintenance staff. Consumption of 40 litres per inhabitant/day is required to meet demand. This represents a total of $100 \mathrm{~m}^{3}$ per day.

Furthermore, during the evaluation performed on the first stage of this project, two underground water storage vessels were found to be the main suppliers of drinking water for the faculty. Each one has a capacity of $10 \mathrm{~m}^{3}$ : The first one is in the library area, and the second one at a garden nearby the FMPS building. Finally, an elevated water storage vessel is also present, having a total volume of $12 \mathrm{~m}^{3}$ [12].

According to the results, drinking water demand is estimated to be $100 \mathrm{~m}^{3} / \mathrm{d}$. This supports that the FMPS building demand had increased; therefore, the water storage system needs to be expanded to meet the current demand [1].

The following investigation proposes to build up an extra $50 \mathrm{~m}^{3}$ capacity cistern, located in the garden adjacent to the FMPS building, with the dimensions of approximately $15 \mathrm{~m} \times$ $3 \mathrm{~m} \times 1.40 \mathrm{~m}$. With the construction of this new cistern, we would reach storage of $70 \mathrm{~m}^{3}$ in underground vessels. To improve the supply system, elevated tanks will be required to be installed: 16 with a capacity of 1,000 litres each. They will be distributed according to a detailed plan (Fig. 3). The installation of these elevated tanks leads to the elimination of the concrete tank that was originally installed with a capacity of $2 \mathrm{~m}^{3}$, weighing 2 tons. These 16 tanks will be distributed in the upper sector of the administrative premises [1].

Due to bad condition or deterioration suffered, eight water storage tanks will be replaced and installed on a terrace in front of the administrative premises.

With this new distribution, the Faculty building would get a total storage volume of $95 \mathrm{~m}^{3}$, satisfying $95 \%$ of the water demand for the FMPS building's population. These elevated tanks will be fed by a pumping unit with a capacity of 1 HP. The storage tanks will be interconnected and installed as shown in Fig. 3.

All pipelines used to interconnect the storage system will be visible; therefore, good quality materials are required, such as polyvinylchloride (PVC) and polypropylene (PP) pipes with ultraviolet (UV) protection, to prevent premature damage to the system.

The three-dimensional (3D) design of the FMPS building and its toilet/sanitary facilities were done with the Revit BIM Software, to simulate the connections of the drinking water network based on the catalogue from the Plastigama company website.

$\mathrm{BIM}$ is an architecture, engineering, construction and operation industry modelling software. The application of this software permits managing the design and modelling of 


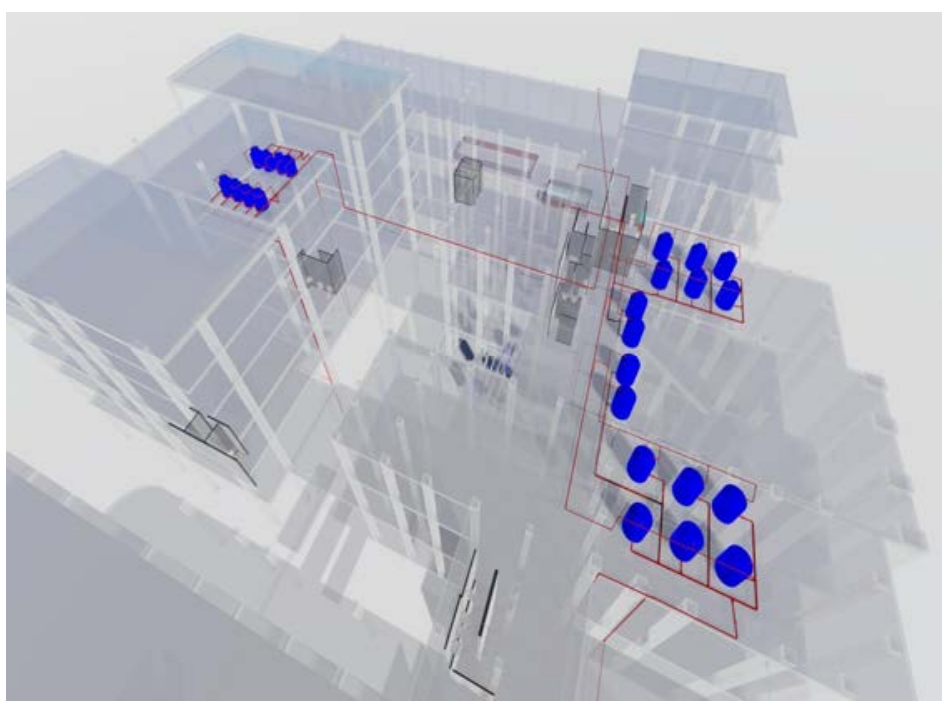

Figure 3: Proposed drinkable water storage system (royal blue) with pipes connected (red).

buildings, project data and facilities throughout their entire useful life. In addition, this software covers several fields, such as: Technology, Process, Policy, Interactions, CAD Format Models, Stages, Data Flows, and Project Life Cycle Phases [8].

To use the program, the building plans are required, then they must be imported into the software; after this, we generated the modelling of the drinking water supply system and the pipe installation scheme (Fig. 4). In Fig. 5, the whole drinking water system is projected in 3D. The BIM library was used, fulfilling the national Ecuadorian standards as required by the NEC.

\section{DATA ACQUISITION}

Consumption and pressure measurements were made in the FMPS building water and sewer network during May 2019. Using statistical calculations, the pressures used for this study's design and remodelling projects were estimated. Based on Table 1, an average pressure of $16.170 \mathrm{mwc}$ was estimated. The flow rates measured provided us with an estimate of $1,700 \mathrm{~m}^{3} / \mathrm{h}$ and $1,730 \mathrm{~m}^{3} / \mathrm{h}$ for each of the original water storage tanks [1].

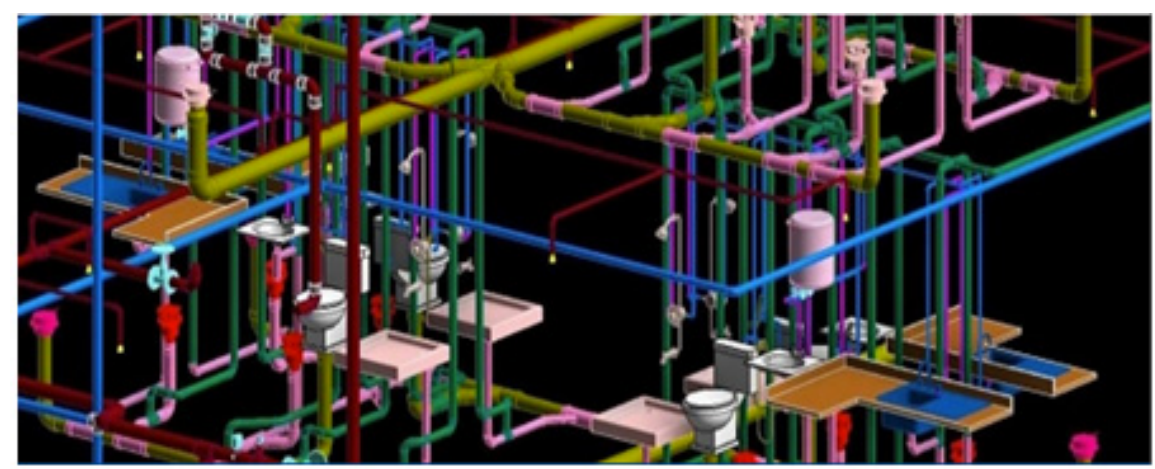

Figure 4: Pipeline modelling and installations generated by BIM. 


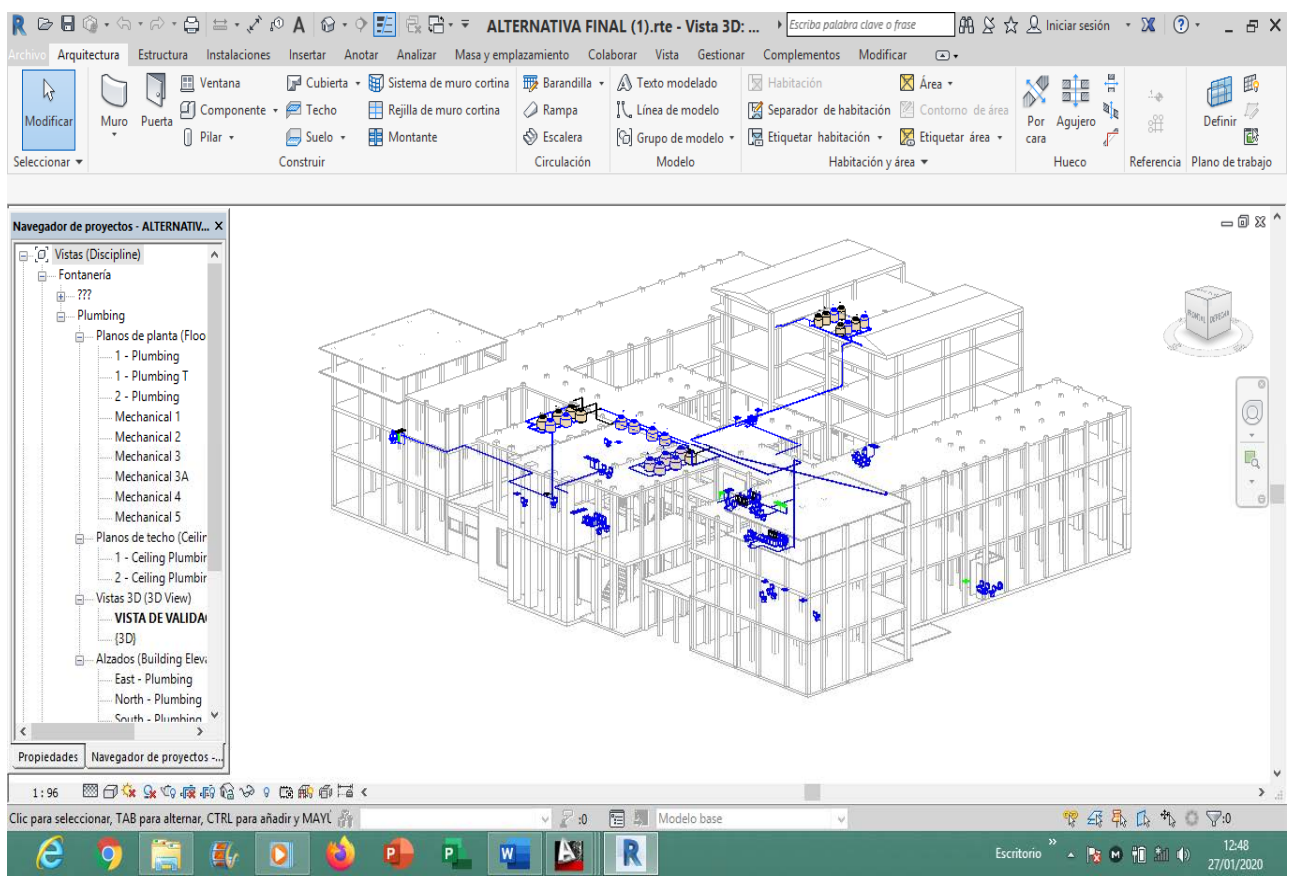

Figure 5: Design of the drinking water installations (blue) for the Faculty of Mathematical and Physical Sciences remodelling project.

Table 1: Pressure measurements obtained from the drinking water network.

\begin{tabular}{|c|c|c|c|c|c|}
\hline \multirow{2}{*}{ Time } & \multicolumn{5}{|c|}{ Pressures and dates (Unit: Meter of the water column (mwc)) } \\
\cline { 2 - 6 } & $05 / 29 / 19$ & $05 / 30 / 19$ & $05 / 31 / 19$ & $06 / 03 / 19$ & $06 / 04 / 19$ \\
\hline 7:00-8:00 & 18.304 & 19.008 & 19.712 & 18.304 & 19.008 \\
\hline 8:00-9:00 & 17.600 & 18.304 & 18.304 & 18.304 & 16.896 \\
\hline 9:00-10:00 & 16.896 & 15.488 & 16.896 & 17.600 & 15.488 \\
\hline 10:00-11:00 & 17.600 & 16.192 & 17.600 & 15.488 & 15.488 \\
\hline $11: 00-12: 00$ & 16.192 & 13.376 & 16.192 & 16.192 & 14.784 \\
\hline $12: 00-13: 00$ & 14.080 & 12.672 & 15.488 & 16.896 & 14.784 \\
\hline $13: 00-14: 00$ & 14.080 & 13.376 & 14.784 & 16.896 & 14.080 \\
\hline $14: 00-15: 00$ & 13.376 & 13.376 & 14.784 & 16.896 & 13.376 \\
\hline $15: 00-16: 00$ & 14.784 & 14.080 & 14.080 & 17.600 & 14.080 \\
\hline $16: 00-17: 00$ & 14.784 & 15.488 & 15.488 & 17.600 & 15.488 \\
\hline $17: 00-18: 00$ & 16.192 & 15.488 & 16.896 & 17.600 & 16.192 \\
\hline $18: 00-19: 00$ & 16.896 & 16.192 & 16.896 & 18.304 & 16.192 \\
\hline $19: 00-20: 00$ & 16.896 & 16.896 & 17.600 & 18.304 & 16.896 \\
\hline
\end{tabular}

\section{WATER STORAGE SYSTEM PROPOSAL DEVELOPMENT}

With all the data gathered regarding water demand, flow rates and the proposed distribution of water storage tanks, we performed a simulation to determine the feasibility of the proposed design (Fig. 6). Corrections were done in the software to guarantee water deliverability to the plumbing system and users. 


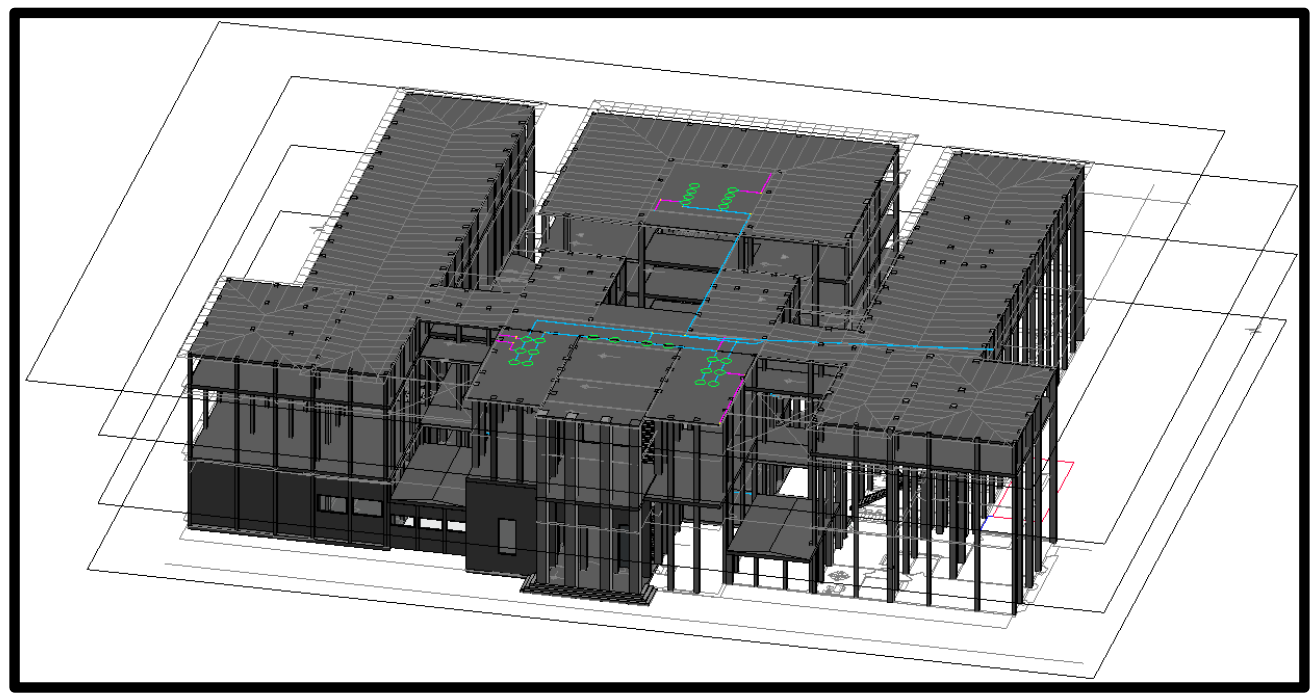

Figure 6: Design showing 3D view of the proposed system simulated by BIM.

Currently, the system has two flow meters installed and is located nearby the underground water storage tanks (cisterns) close to the FMPS complex. They record the drinking water flow rates to be stored in other cisterns located in the FMPS building. From the underground storage, the water is sent to the elevated storage tanks by pumping units and finally, the stream gets to the user by gravity. In this whole process, pressure is considered a critical parameter for water deliverability assurance.

Different modelling options were options considered in this proposal (Figs 7-12).

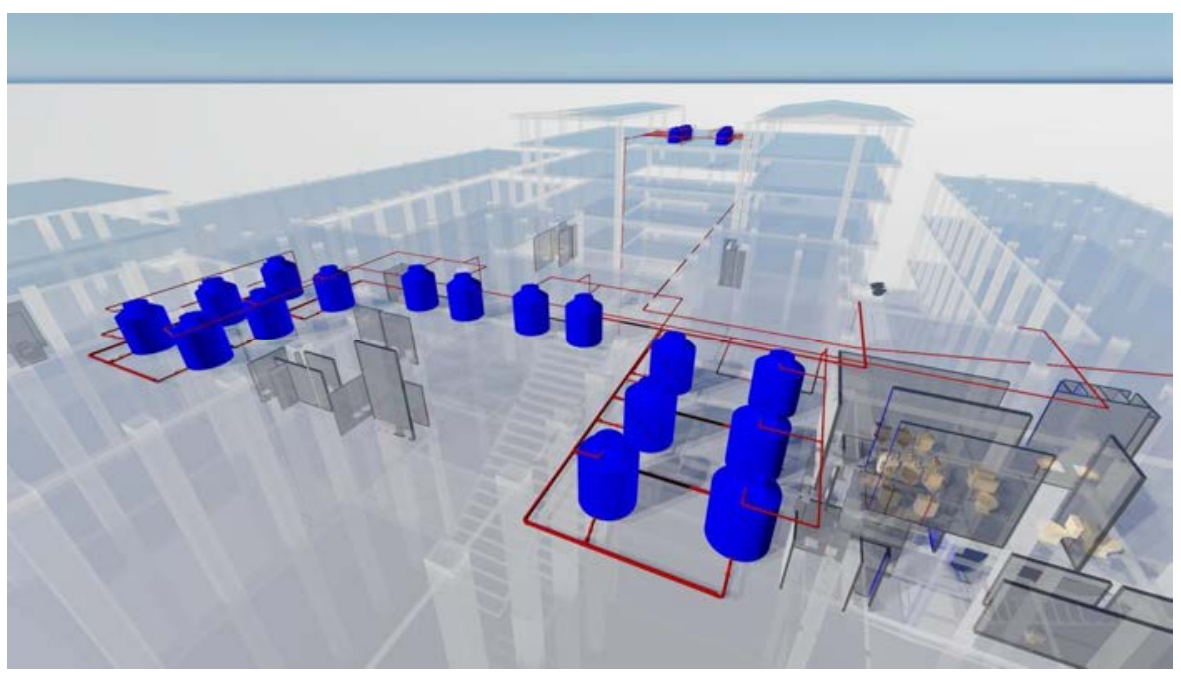

Figure 7: Water storage tank distribution (royal blue) in the main terrace of the administrative premises of the Faculty of Mathematical and Physical Sciences building. 


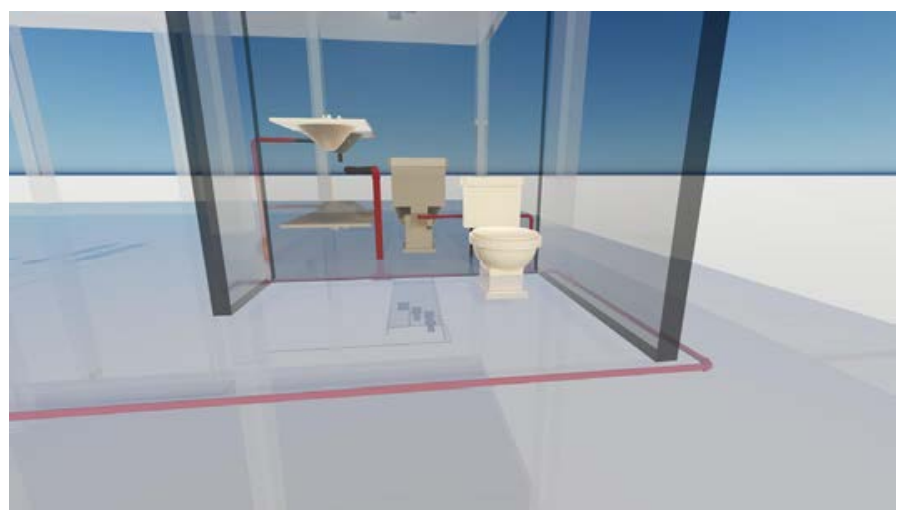

Figure 8: Model for improvement proposal regarding new pipes (red) and their accessories (cream) in a restroom/lavatory area.

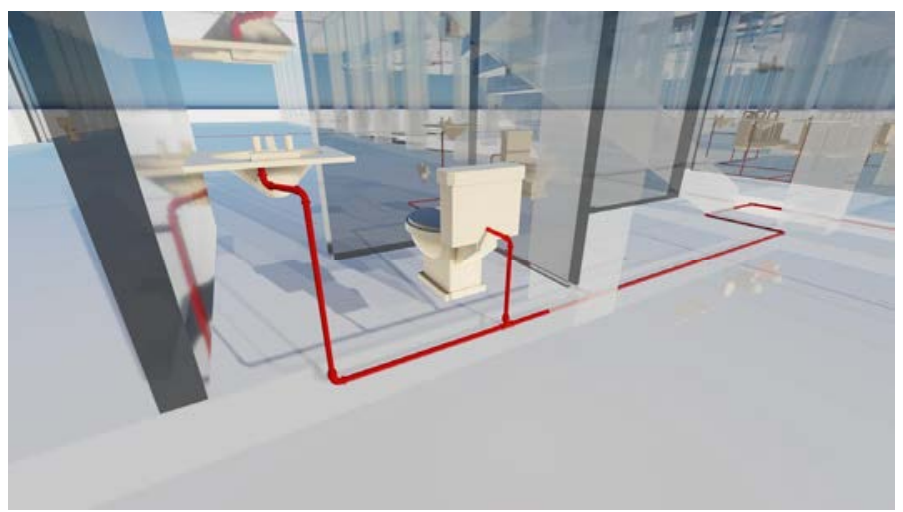

Figure 9: Drinking water (incoming, red) network design using the Plastigama catalogue.

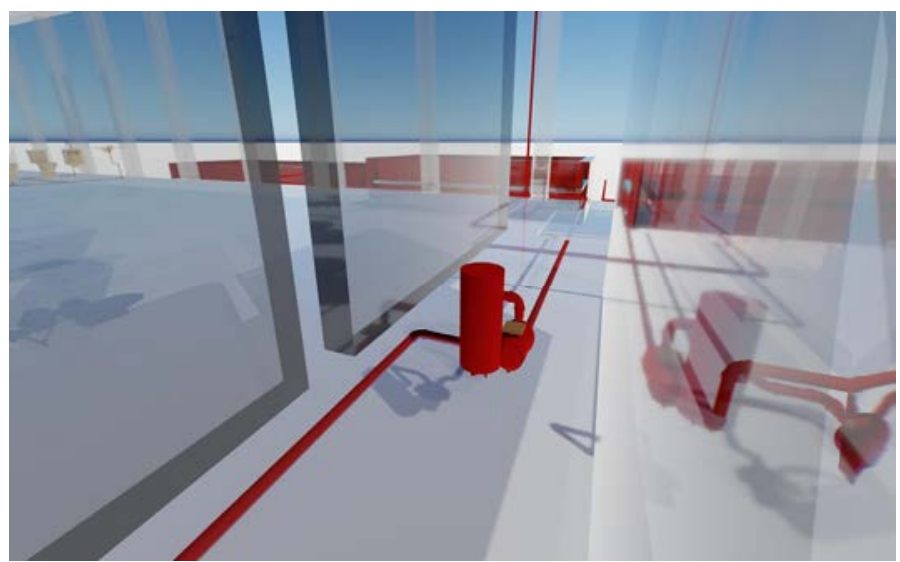

Figure 10: Pumping system units (red) needed to deliver water to the elevated tanks. 


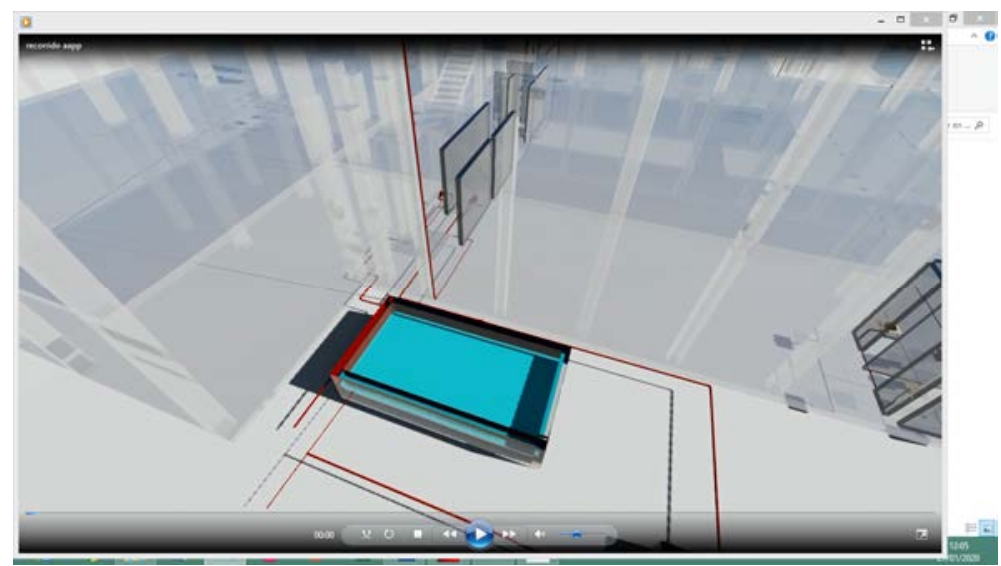

Figure 11: Cistern (turquoise) to be located in the Faculty of Mathematical and Physical Sciences building's garden.

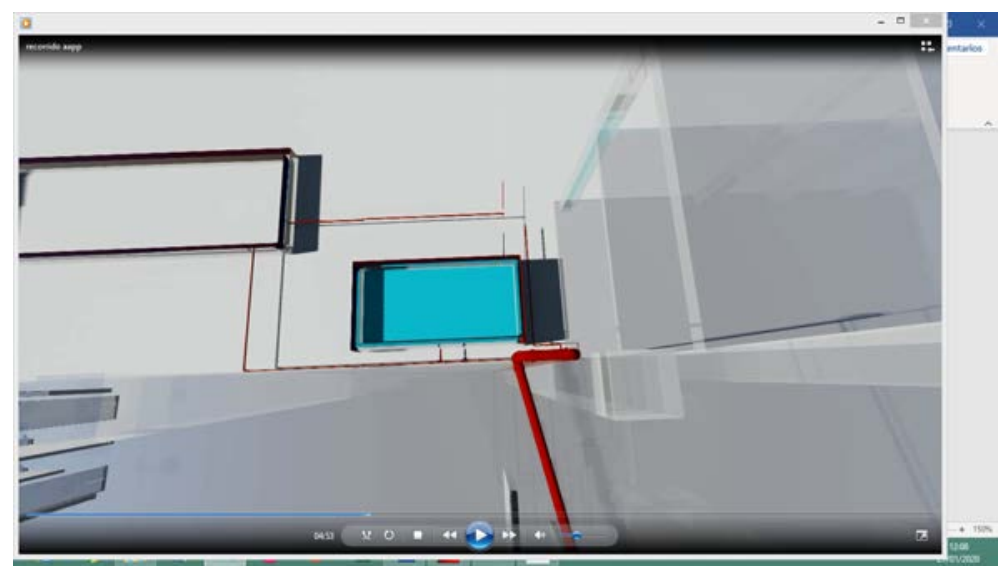

Figure 12: Location of the current working cistern (gray) and the proposed one (turquoise) to be built.

\section{RAINWATER SEWAGE}

In the first stage of the project, we discovered that the sewage and the rainwater diversion systems were interconnected. These interconnections were in the physics lab and library areas. Inspecting the area on foot, several slopes were found in the lateral and rear areas. This topographic condition was taken as an opportunity by the surroundings faculty buildings, which installed their drainage systems to lead to the sewage collector at the rear area of the Faculty of Mathematical and Physical Sciences building (Fig. 13).

We proposed the implementation of an evacuation channel for rainwater after a detailed topography study was completed. This channel will collect the rainwater from the surroundings and conduct them to a sink located beside a sidewalk. We used Revit software for modelling the proposal and Lumino software permitted a 3D video tour. These videos are available and access links are provided in the references [13], [14]. 


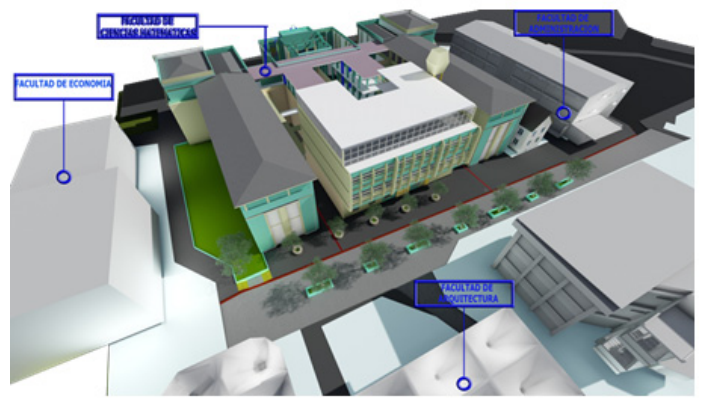

Figure 13: Front view of the Faculty of Mathematical and Physical Sciences building, showing drains in red, and surrounding buildings tagged in blue.

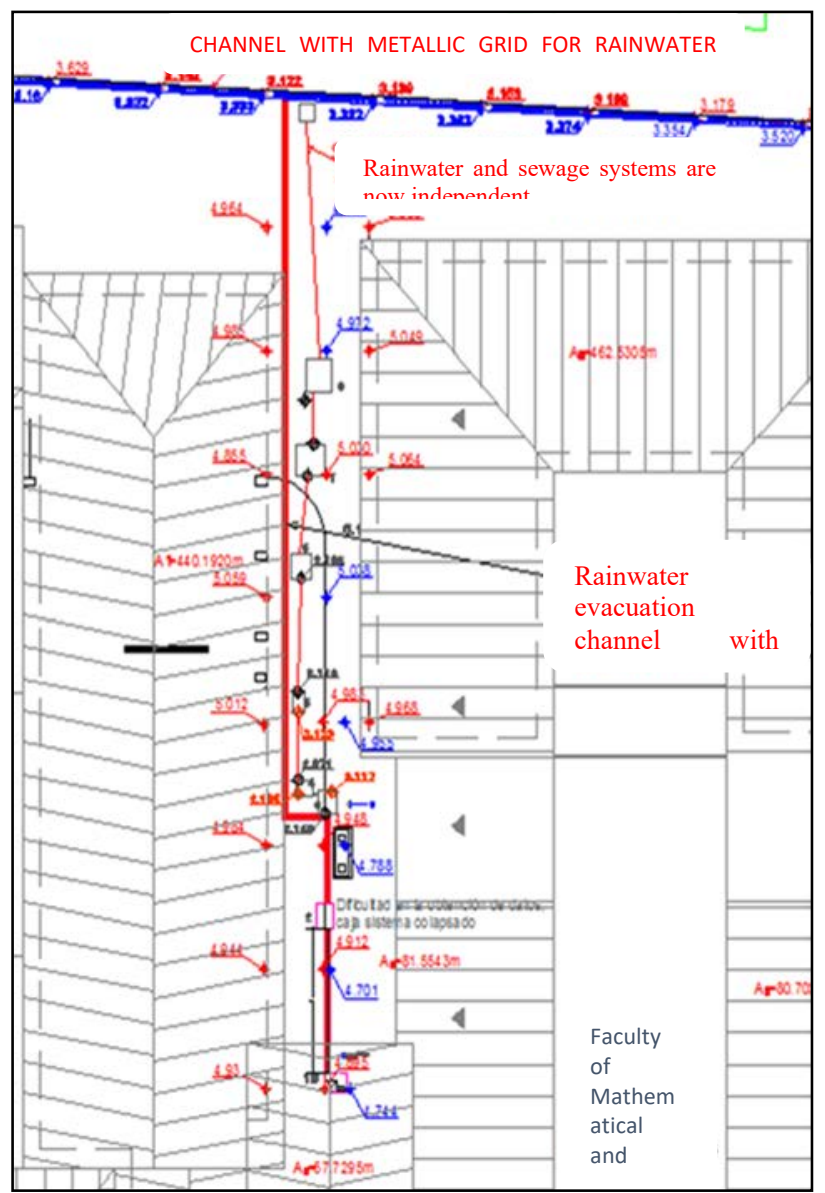

Figure 14: Rainwater evacuation plan (thick red line) inside the premises of the Faculty of Mathematical and Physical Sciences building towards the channel (thick blue) located at the rear of the building. Note that sewage system pipes near the faculty building (thin red) are now independent from the rainwater channel. 
Rainwater evacuation channels are shown in Fig. 14, as well as the Physics laboratory and Library area where the rainwater boxes and the wastewater boxes are. The rainwater drainage and the sewer system have now been separated: there are two rainwater discharge systems, consisting of a duct channel with covered grids, also shown in Fig. 14.

In the rear area of the FMPS building, a gutter-type evacuation channel was proposed, which runs from the rear of the Faculty of Mathematical and Physical Sciences building adjacent to the Faculty of Architecture; then, this channel connects to the Faculty of Administration's channel, and later discharges laterally into the drain located in the sidewalk in front of the Faculty of Administration, as seen in Figs 15 and 16.

In the front area of the building, the rainwater discharge sewers become connected to the sidewalk drains that flush into the Faculty of Administration. All the rainwater drainpipes of the building will be connected to the new rainwater evacuation channel proposed in the FMPS building's rainwater system improvement project (Figs 15 and 16).

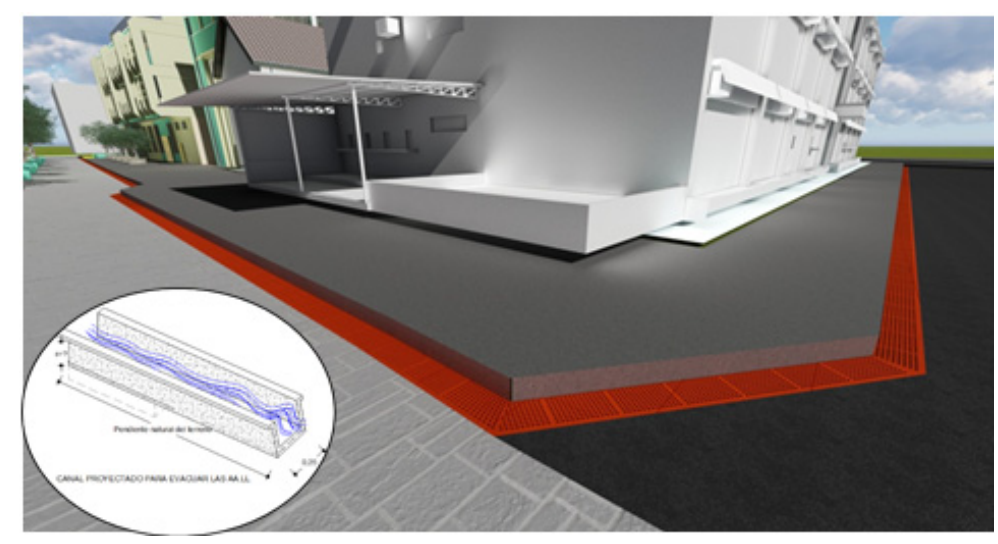

Figure 15: Proposed rainwater evacuation plan (red) for the Faculty of Mathematical and Physical Sciences' premises.

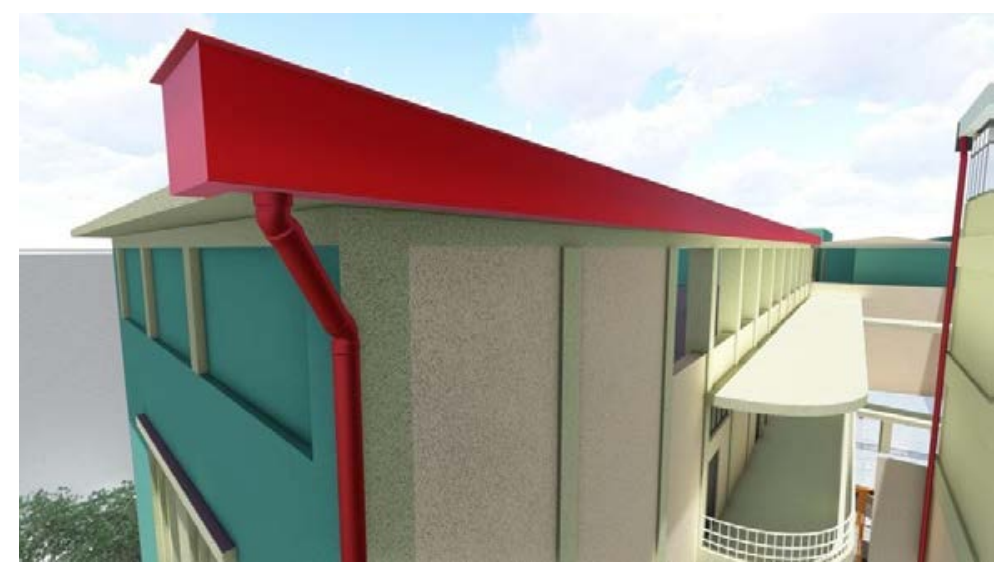

Figure 16: Rainwater drainpipes (red) leading to the evacuation channel proposed in our project. 


\section{LAVATORY FACILITIES INSTALLED AT FMPS BUILDING}

According to the evaluation of the FCI-050 Project, "Evaluation of the Sanitary and Pluvial Sewer System of the Faculty of Mathematical and Physical Sciences of the University of Guayaquil" [1], the currently installed sanitary systems are insufficient for the existing overall population of the FMPS building complex. So at this first stage, the lavatory facilities were found insufficient.

The largest population being served by the lavatory facilities is the students.

Table 2: Sanitary facilities in the Faculty of Mathematical and Physical Sciences building at the University of Guayaquil, Ecuador, selected by user type and sex.

\begin{tabular}{|l|c|c|c|}
\hline \multicolumn{4}{|c|}{ Lavatory facilities } \\
\hline & Sinks & Lavatory & Urinal \\
\hline Male students & 9 & 4 & 37 \\
\hline Female students & 4 & 4 & 0 \\
\hline Male lecturers & 0 & 1 & 2 \\
\hline Female lecturers & 0 & 0 & 0 \\
\hline
\end{tabular}

\section{CONCLUSIONS}

The building complex for the Faculty of Mathematical and Physical Sciences in the University of Guayaquil, Ecuador, has drinking water networks that are in bad condition due to corrosion, as they have exceeded their useful life. Therefore, the University administration must change the entire drinking water system, the water storage tanks, and expand the volumes of water reserves to supply the current demand for water of the faculty's building based on its user population, as well as the implementation of new sanitary devices.

Sanitary facilities in the men's restrooms need to be expanded by nine toilets, four sinks and 36 urinals. On the other hand, facilities for women are sufficient [1].

To meet the water demand of the FMPS facilities users, 16 tanks of 1,000 L must be installed, distributed on the terrace of the main faculty building.

Our topographic survey revealed that the FMPS building's levels are lower at the rear of the building, which is the cause of flooding seen during the rainy season. Unfortunately, this tiered condition cannot be easily repaired; therefore, it is necessary to separate the rainwater discharge from the regular sewage system, to evacuate both more quickly, which is the best solution for rainfall-related flooding proposed in the present investigation.

\section{RECOMMENDATIONS}

We recommend implementation of a permanent maintenance plan to increase the new facilities' durability, and monitoring of the quality of water delivered and disposed of throughout the process. This plan should include leak monitoring.

To reduce flooding in the rear area of the faculty building, we recommend permanently evacuating garbage from the sewage system and evacuation channels.

To reduce water consumption, we believe it is necessary to install automatic water dispensers, flushometres, and tanks for toilets with a reservoir raised to $1.5 \mathrm{~m}$ of $4 \mathrm{~L}$ to reduce water consumption. 


\section{REFERENCES}

[1] Saltos Sánchez, A., Rojas, J., Villa Ríos, P. \& Tobar Barreno, G., Evaluación del sistema de alcantarillado sanitario y pluvial de la Facultad de Ciencias Matemáticas y Físicas de la Universidad de Guayaquil [Evaluation of the plumbing and rainwater gutter system at the University of Guayaquil's Faculty of Mathematical and Physical Sciences building]. Revista Ciencia e Investigación [Journal of Science and Research], 3(ICCE2018), pp. 16-27, 2018. https://revistas.utb.edu.ec/index.php/sr/ article/view/586.

[2] Meride, Y. \& Ayenew, B., Drinking water quality assessment and its effects on residents' health in Wondo genet campus, Ethiopia. Environmental Systems Research, 5(1). DOI: 10.1186/s40068-016-0053-6.

[3] Huttinger, A. et al., Water, sanitation, and hygiene infrastructure and quality in rural healthcare facilities in Rwanda. DOI: 10.1186/s12913-017-2460-4.

[4] González-Amarillo, C.A., Cárdenas-García, C.L. \& Mendoza-Moreno, M.A., M2M system for efficient water consumption in sanitary services, based on intelligent environment. DYNA (Colombia), 85(204), pp. 311-318, 2018.

[5] Blasco, E.J., Instalaciones sanitarias en edificaciones. Lima, Perú: Colegio de Ingenieros del Perú [Plumbing Installations in Buildings in Lima, Peru]. College of Engineers of Peru, 2005.

[6] Cheng, C.-L., Peng, J.-J., Ho, M.-C., Liao, W.-J. \& Chern, S.-J., Evaluation of water efficiency in green building in Taiwan. Water, 8(6), p. 236, 2016.

DOI: $10.3390 / \mathrm{w} 8060236$.

[7] Salvo, P., Sparling, M. \& Telmosse, R., Higher education - University of Ottawa investigates to identify underground infrastructure academic grade. NASTT's 2018 No-Dig Show, 2018.

[8] Silva, A.S. \& Ghisi, E., Uncertainty analysis of daily potable water demand on the performance evaluation of rainwater harvesting systems in residential buildings. Journal of Environmental Management, pp. 82-93, 2016.

[9] Bartkiewicz, E. \& Zimoch, I., Analysis of the risk of pipe breaks based on hydraulic model. Safety and Reliability - Safe Societies in a Changing World, pp. 1511-1516, 2018.

[10] Angulo, C.M., Aplicación de metodología BIM para la optimización en los diseños hidrosanitarios en las edificaciones [BIM usage methods for optimizing hydrosanitary designs for buildings]. Universidad Francisco De Paula Santander, 2020.

[11] Fadoul, A., Tizani, W. \& Osorio-Sandoval, C.A., A knowledge-based model for constructability assessment of buildings' design using BIM, Lecture Notes in Civil Engineering, vol. 98, pp. 147-159, 2020.

[12] Carmona, R.P., Instalaciones hidrosanitarias, de gas y de aprovechamiento de aguas de lluvia [Hydrosanitary plumbing installation, gas installation, and use of rainwater], 2015.

[13] Saltos, A., 2021. Sewer system tour.

https://www.youtube.com/watch? $v=M B n H z t p h h a E \&$ feature=youtu.be. Accessed on: 15 Feb. 2021.

[14] Saltos, A., 2021. Drinking water tour. https://www.youtube.com/watch? $\mathrm{v}=\mathrm{MBnHztphhaE \& feature=youtu.be.} \mathrm{Accessed} \mathrm{on:}$ 15 Feb. 2021. 